\title{
STUDY OF PEEK AS A FRICTION LINING CONCERNING ABRASION WEAR OF PARTS OF MINING MACHINES
}

\begin{abstract}
A. Niemiec ${ }^{*}$, Sokolska**
Abstract: With a growing awareness of engineering polymers, there is an increasing application of polymers and polymeric composites for machine elements. Because of their relatively low cost of manufacturing and ability to work without lubrication in contact with different types of materials, especially at increasing temperatures polymers are more often applied. This paper investigates the wear behaviour of poly etherether-ketone (PEEK) as a frictional lining of parts of mining machines. PEEK and its composites, reinforced with carbon, aramid and glass fibres, were analysed over their wear and frictional properties as well as their potential damage mechanisms.
\end{abstract}

Keywords: PEEK, abrasive wear, wear resistance, frictional materials

\section{Introduction}

Abrasion is the most common type of wear in industrial practice. It can occur in all places, where rigid particles can go between sliding surfaces, where the surface roughness is high or the hardness of the sliding elements is very different, or if the machine works with an abrasive material. One of the most significant operational parameters in machines is wear resistance. It is especially important in cases of operation in such disadvantageous environments like mines where machines work under influence of highly abrasive particles. To lower that negative impact, among others coatings are used to protect surfaces vulnerable to wear (Ziolkowska, 2017). Those coatings most of all are applied to belt conveyors systems. On the other hand, undercarriages units of large-size working machines are also endangered to such an influence but polymer materials are not used inside tribological nodes of those assemblies. Other methods of improvement of durability are applied like steel bushings (Sokolski, 2014). It is because of much higher values of loadings. Abrasion wear is one of the most common failure mechanisms of moving machine elements. The abrasivity of rock, coal and even soil is a factor with considerable influence on the wear of parts of machines and tools. Examples of such conditions are mines where other polymer material (polyurethane) is already used. The polymers and polymer composites can be chosen as sliding materials, because of their good deformation ability, in abrasive applications during the machine construction also as a counter measure. Polymer composites can also improve the tribological properties of the base polymers in an abrasion friction system. It helps to decrease wear rate in tribological pairs which operation is characterized by high value of coefficient of friction and loading (Ziolkowska, 2017). Tribological performance of a system can be improved by replacing conventional metallic materials with high performance polymers. Nowadays, there is a significant potential growth in the use of ceramics and polymers with the purpose of protection of components subjected to wear. This work has compared the tribological performance of engineering polymer and its composites, namely poly-ether-ether-ketone, glass, aramid and carbon fibre reinforced PEEK and PEEK filled with polytetrafluoroethylene (PTFE).

Poly-ether-ether-ketone (PEEK) is one of the most promising polymers, a semi-crystalline thermoplastic with excellent mechanical properties (Kujawa et al., 2017). It displays high glass transition temperature

Aneta Niemiec, MSc. Eng..: Faculty of Mechanical Engineering, Wroclaw University of Science and Technology,

Lukasiewicza Street 4; 50-371 Wroclaw; PL, aneta.niemiec@pwr.edu.pl

** Justyna Sokolska, MSc. Eng.: Faculty of Mechanical Engineering, Wroclaw University of Science and Technology, Lukasiewicza Street 4; 50-371 Wroclaw; PL, justyna.sokolska@pwr.edu.pl 
$\left(143{ }^{\circ} \mathrm{C}\right)$ and high melting point $\left(335^{\circ} \mathrm{C}\right)$ (Jones et al., 1985). It can be easily processed in various complex shapes and also it possesses high toughness, excellent thermal properties, biocompatibility and excellent wear resistance (Lu et al., 1995). It has good stability in both chemically active and radiation environments. PEEK and its composites are widely used for various applications e.g. aerospace, nuclear, oil and gas industry, food and packing, automotive, electrical and chemical industries, biomedical and tribological, among others (Hoskins, et al., 2014). The aromatic rings in this polymer backbone are responsible for its strength, heat and radiation resistance (Blundell et al., 1983). PEEK's properties provide resistance to abrasive and fatigue wear, and it is a naturally low friction material (Laszlo et al., 2016 and Cirino et al., 1987).

The aim of this work is to compare the abrasive wear resistance of PEEK and its composites, and to compare the performance with conventional material which is polyurethane (PU) used as the frictional lining of parts of mining machines.

\section{Tribological properties of neat PEEK and its composites}

Natural PEEK is a semi-crystalline advanced material that exhibits a unique combination of high mechanical properties, temperature resistance and an excellent chemical resistance. Unfilled PEEK provides superior fatigue resistance and good wear resistance as well, provided the maximum stress and velocity are low (Jones et al., 1985). Exemplary surface damage wear mechanisms: abrasive and adhesion wear, in unfilled PEEK were shown in Fig.1., showing disadvantageous influence of abrasive particles on a sliding surface. Polymer would appear to be an ideal gear material, because of its high relative thermal index for mechanical contact with impact suggests that it is capable of withstanding the high temperatures and stresses associated with high performance polymeric gearing without significant thermal degradation (Avanzini et al., 2013). The main properties are a high service temperature (permanently around $250{ }^{\circ} \mathrm{C}$, briefly to $310{ }^{\circ} \mathrm{C}$ can be used), stiffness, excellent chemical hydrolysis and good dimensional stability. In the unreinforced polymer, friction was shown to correlate well with both temperature and wear. Temperature dominates all aspects of the performance and design of polymer machine elements. The friction coefficient of PEEK decreases with increasing temperature, it passes through an optimum point (around the glass transition temperature at $143^{\circ} \mathrm{C}$ ) and then increases slightly (Rae et al., 2007).

a)

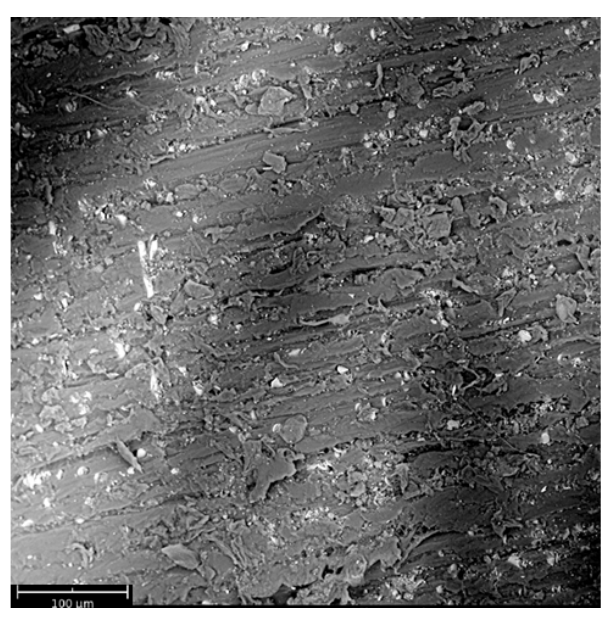

b)

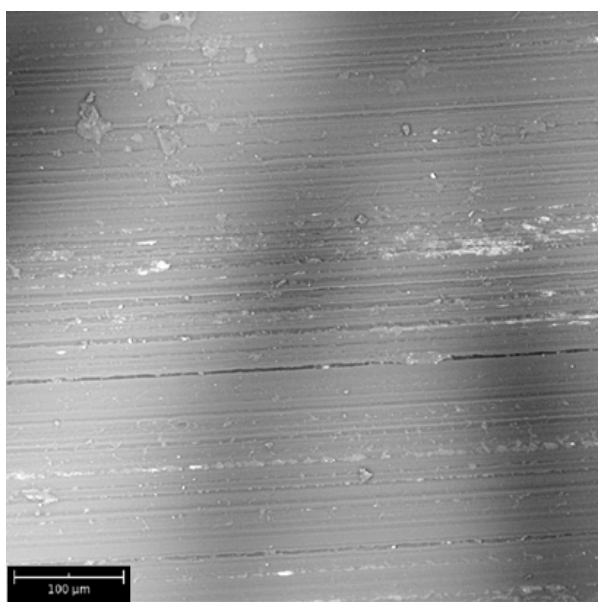

Fig. 1: Surface damage wear mechanisms in unfilled PEEK: (a) abrasive wear; (b) adhesion wear (Author's archive).

Working with polymer composites opens a wide range of opportunities to develop new or better materials. PEEK components can be fiber reinforcements, binders, friction modifiers and fillers. Typical fibers are carbon, glass, aramid, cellulosic fiber and thermoplastic fiber. Aramid fiber is the most effective in improving the resistance when it was in normal orientation. 


\subsection{PEEK reinforced with glass fiber}

Glass fiber is isotropic and have an amorphous microstructure. It is relatively cheap, but has week heat resistance causes fade, low wear characteristic and unsteady coefficient of friction. Moreover one of the problems with glass fiber is losses of fiber form in high shear mixing, molding and springs back. PEEK composite contains $30 \%$ glass fiber reinforced for greater dimensional stability and higher strength properties. Unfortunately it has the highest wear with a lower hardness among other PEEK composites. Glass fiber has negative effect on the friction and the wear at abrasive surface (Cirino et al., 1987 and Laszlo et al., 2016).

\subsection{PEEK reinforced with carbon fiber}

The microstructure of the carbon fibers consists of carbon atoms covalently bonded in layers parallel to the fiber axis but with relatively weak bonding between the layers in the radial direction. This gives way to weak planes for sites of cleavage running axially resulting in larger cut fiber pieces. Disadvantageous of carbon fiber is its high price and problem with losses of fiber form in mixing. PEEK composite containing carbon fiber shows better results in connection of friction coefficients and wear among PEEK composite containing glass fiber (resulted in relative increase in the wear rate and the coefficient of friction). Short carbon fibers proved better for improving wear resistance as compared to short glass fibers. The wear rate of the PEEK carbon fiber reinforced composite with different fiber volume increased with increasing temperature, in particular by about 1.5 orders of magnitude within the temperature range from $20-220^{\circ} \mathrm{C}$. More than 20 vol. \% carbon fibers can cause stick-slip behavior, especially at very high testing temperatures e.g. $220^{\circ} \mathrm{C}$ (Cirino et al., 1987 and Lu et al., 1995).

\subsection{PEEK reinforced with aramid fiber}

Aramid fiber has a high thermal stability, good wear properties and stable coefficient of friction. Despite the wide range of advantages, it is a costly fiber. This disadvantage has to be taken into account when decided to use this fiber material. An ideal low wear composite material would consist of a PEEK matrix reinforced with aramid fibers oriented normal to the contacting surface and carbon fibers oriented parallel to the contacting surface (Cirino et al., 1987).

\subsection{PEEK reinforced with PTFE}

The inclusion of PTFE reduce the quite high coefficient of friction of PEEK. To create a continuous transfer layer, solid lubricants like graphite and PTFE are commonly used. More investigations describe that the PEEK that is alloyed with PTFE provides low wear rates at high pressure-velocity conditions in even abrasive environments. Such material is produced for tribological applications with high requirement of long service life under extreme loading and environmental conditions. The influence of increasing the amount of PTFE in PEEK showed that the PTFE significantly benefited both coefficient of friction and the specific wear rate of PEEK. However, with an increase in PTFE, coefficient of friction decreased continuously. From 12 to $18 \%$ loading range of PTFE was found to be optimal for the friction and wear combination. PEEK filled with $20 \%$ of PTFE offers a lower coefficient of friction and improved wear rates over the unfilled one. The wear properties influences sliding speed and load. The sliding velocity effects on the wear properties of PEEK, proved that the sliding velocity has a more significant effect on the wear properties of polymer than the apparent contact pressure (Lu et al., 1995).

\section{Abrasive wear of PU}

Polyurethane elastomers are largely applied to industry and consumer products, particularly in the fields of heavy pressure, load, impact and wear because they possess excellent comprehensive properties such as high wear, oil and corrosion resistance, high elasticity and damping, good adhesion to other materials and so on. PU is being used as wear resistant material to replace traditional metallic materials in the mineral and mechanical industries. This polymer has some disadvantages like poor heat resistance and high costs. 


\section{Conclusions}

Among the investigated polymers and their composites, neat PEEK is the most suitable sliding material, because its friction is lowest and its wear resistance is higher. The PEEK composites are suitable as machine elements in normal abrasive applications, as they resist against abrasion wear. If there are any demands for example: high mechanical properties, temperature resistance and excellent chemical resistance etc., it is important to know the character of the filling. The abrasion tests with PEEK polymer and composites with abrasive surface will provide new information about their tribological behavior and show new possibilities for practical application.

Composite friction materials were developed alongside with the evolution of brake, clutch and industrial application of construction. There are still open questions about friction behavior under different conditions, wear characteristic sensitivity, loads and responses, manufacturing steps etc. The field of composite frictional materials is so wide spread and still an undeveloped land, that it grants a wide range of research opportunities for present and future investigations, experiments and studies.

\section{References}

Avanzini, A., Donzella, G., Mazzu, A., Petrogalli, C. (2013) Wear and rolling contact fatigue of PEEK and PEEK composites. Tribology International, 57, pp. 22-30.

Blundell, D.J., Osborn, B.N. (1983) The morphology of poly(aryl ether ether-ketone). Polymer, 25, pp. 953-958.

Cirino, M., Pipes, R.B., Friedrich, K. (1987) The abrasive wear behavior of continuous fibre polymer composites. Journal of Materials Science, 22, pp. 2481-2492.

Hoskins, T.J., Dearn, K.D., Chen, Y.K., Kukureka, S.N. (2014) The wear of PEEK in rolling-sliding contactsimulation of polymer gear applications. Wear, 309, pp. 35-42.

Jones, D.P., Leach, D.C., Moore, D.R. (1985) Mechanical properties of poly(ether-ether-ketone) for engineering applications. Polymer, 26, pp. 1385-1393.

Kujawa, M., Wieleba, W. (2017) The influence of a constant state of deformation on the friction coefficient in selected thermoplastics (polymer-steel pair). Tribologia, 4, pp. 39-45.

Laszlo, Z., Laszlo, K. (2016) Abrasive wear and abrasion testing of PA6 and PEEK composites in small-scale model system. Acta Polytechnica Hungarica, 6, pp. 197-214.

Lu, Z.P., Friedrich, K. (1995) On sliding friction and wear of PEEK and its composites. Wear, 181-183, pp. 624631.

Rae, P.J., Brown, E.N., Orlen, E.B. (2007) The mechanical properties of poly(ether-ether-ketone) (PEEK) with emphasis on the large compressive strain response. Polymer, 48, pp. 598-615.

Sokolski, P. and Sokolski, M. (2014) Evaluation of resistance to catastrophic failures of large-size caterpillar chain links of open-pit mining machinery. Eksploatacja i Niezawodnosc - Maintenance and Reliability 2014; 16 (1), pp. 80-84.

Ziolkowska, J. (2017) Polyurethane coatings and methods of examination of their properties. Engineering Mechanics 2017, Brno University of Technology, Brno, pp. 1130-1133. 